\title{
Investigation of the Antimicrobial Activity of Hospital Furniture Coated with Melamine Resin Endowed with Catalysts as In Situ Generated Biocides
}

\author{
Guggenbichler $\mathbf{S}^{1}, \mathbf{M ~ H e l l}^{2}$ and Guggenbichler JP ${ }^{3 *}$ \\ ${ }^{1}$ Division for Vascular Surgery and Endovascular Surgery of the University Clinic for Cardiac Surgery, Vascular Surgery and \\ Endovascular Surgery, Paracelsus Medical University Salzburg, Austria
}

${ }^{2}$ MEDILAB, Teaching Laboratory of the Paracelsus Medical University Salzburg, Department of Clinical Microbiology and Infection Control, Salzburg, Austria

${ }^{3}$ Department or Pediatrics, AmiSTec GMbH und Co KG, Kössen, Austria

*Corresponding author: Guggenbichler JP, Department or Pediatrics, Univ. Erlangen, AmiSTec GMbH und Co KG, Kössen, Austria

\section{ARTICLE INFO}

Received: 蔧 May 03, 2021

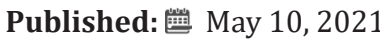

\section{ABSTRACT}

Citation: Guggenbichler S, M Hell, Guggenbichler JP. Investigation of the Antimicrobial Activity of Hospital Furniture Coated with Melamine Resin Endowed with Catalysts as In Situ Generated Biocides. Biomed J Sci \& Tech Res 35(4)-2021. BJSTR. MS.ID.005737.

\section{Introduction}

For people in the 21st century, it is hard to imagine the world before antibiotics. At the beginning of the 20th century, as many as nine women out of every 1,000 who gave birth died, 40 percent from sepsis. In some cities as many as 30 percent of children died before their first birthday. One of every nine people who developed a serious skin infection died, even from something as simple as a scrape or an insect bite. Pneumonia killed 30 percent of those who contracted it; bacterial meningitis was almost universally fatal. Ear infections caused deafness; sore throats were not infrequently followed by rheumatic fever and heart failure. Surgical procedures were associated with high morbidity and mortality due to infection. This picture changed dramatically with three major developments: improvements in public health, vaccines, and antibiotics. Over the course of the 20th century, deaths from infectious diseases declined markedly and contributed to a substantial increase in life expectancy.

Antibiotics have saved millions of lives. But the world is now at dire risk of losing this progress. Bacteria and other microbes evolve in response to their environment and inevitably develop mechanisms to resist being killed by antibiotics but Increasing tolerance of hospital Enterococcus faecium to handwash alcohols $[1,2]$. For many decades, the problem was manageable as the growth of resistance was slow and the pharmaceutical industry continued to create new antibiotics. Over the past decade, however, this brewing problem has become a crisis. The evolution of antibiotic resistance is now occurring at an alarming rate and is outpacing the development of new countermeasures capable of thwarting infections in humans [3-7]. This situation threatens patient care, economic growth, public health, agriculture, economic security, and national security. The UN Interagency Coordination Group on Antimicrobial Resistance demands therefore immediate, coordinate and ambitious measures to combat this problem [8].

\section{The Problem}

Intensive care unit (ICU)-acquired infections are a challenging health problem worldwide, especially when caused by multidrugresistant (MDR) pathogens and a daily challenge for the clinician dealing with critically ill patients. Contamination of inanimate surfaces in ICU has been identified in outbreaks and crosstransmission of pathogens among critically ill patients. In ICUs, inanimate surfaces and equipment (e.g., bedrails, stethoscopes, medical charts, ultrasound machine) are frequently contaminated by bacteria, including MDR isolates [9]. Contamination may occur either by transfer of microorganisms contaminating healthcare workers' hands or direct patient shedding of microorganisms in the immediate environment of a patient's bed. Multi drug resistant (MDR) bacteria have been reported as contaminating 
microorganisms of surfaces, commonly used medical equipment and high-contact communal surfaces (e.g., telephones, keyboard, medical charts) in ICU [8]. It has been reported that both Grampositive and Gram-negative bacteria are able to survive up to months on dry inanimate surfaces, with even longer persistence under humid and lower-temperature conditions [10]. Environmental contamination by fungi and viral pathogens including coronavirus has been also described not only in ICU. Factors that may affect the transfer of microorganisms from one surface to another and crosscontamination rates are type of organisms, source and destination surfaces, humidity level, and size of inoculum [11-13].

Cross-transmission of microorganisms from inanimate surfaces may have a significant role for ICU-acquired colonization and infections. A higher environmental contamination has been reported around infected patients than around patients who are only colonized, in this last group, a correlation has been observed between frequency of environmental contamination and culturepositive body sites. Admission to a room previously occupied by a patient with MRSA, VRE, Acinetobacter, or C. difficile increases the risk for the subsequent patient admitted to the room to acquire the pathogen [14]. Healthcare workers not only contaminate their hands after direct patient contact but also after touching inanimate surfaces and equipment in the patient zone (Beste Übersetzung von „Patientennahen Oberflächen") [15,16]. Quartile distribution of health care acquired infections stratified by microbial burden were measured in the intensive care unit rooms during patients stay. A significant association between burden and HAI risk with an $89 \%$ risk occurring in a room when $100 \mathrm{~cm}^{2}$ surfaces were contaminated by more than $10^{5} \mathrm{CFU}$ [17].

Contamination of inanimate surfaces in ICU has been identified in outbreaks and cross-transmission of pathogens among critically ill patients. Contamination may occur either by transfer of microorganisms contaminating healthcare workers' hands or direct patient shedding of microorganisms in the immediate environment of a patient's bed. Multi drug resistant (MDR) bacteria have been reported as contaminating microorganisms of surfaces, commonly used medical equipment and high-contact communal surfaces (e.g., telephones, keyboard, medical charts) in ICU $[18,19]$. Factors that may affect the transfer of microorganisms from one surface to another and cross-contamination rates are type of organisms, source and destination surfaces, humidity level, and size of inoculum [20]. However, other factors playing a role in contamination and cross-transmission rate in the ICU may include hand hygiene compliance, nurse-staffing levels, frequency/ number of colonized or infected patients, ICU structural features (e.g., single-bed or multi-bed ICU rooms) and adoption of antibiotic stewardship programs. The issue of environmental contamination may pose an even greater challenge in the ICU, where patients are critically ill, with several risk factors for nosocomial infections [21] and the highest standard measures for infection prevention cannot always be addressed due to impelling, life-threatening conditions. Moreover, the nearby environment of ICU beds is crowded by equipment for monitoring and support, with many hand-touch sites, requiring sophisticated and specific cleaning procedures. Identifying which sites are more frequently contaminated and what the most identified contaminants are may play a major role for infection control practices and promotion of new interventions.

Improved surface cleaning and disinfection has been anticipated to reduce transmission of these pathogens and the risk of healthcare-associated infections. Contact with the contaminated environment by healthcare personnel is equally as likely as direct contact with a patient can lead to contamination of the healthcare provider's hands or gloves that may result in patient-to-patient transmission of nosocomial pathogens. Both detergent- and disinfectant-based cleaning have been used to control these pathogens, although difficulties arose with the soaring resistance of pathogens to disinfectants. Most disinfectants are not resulting in a reliable and lasting decontamination of surfaces anymore [22]. There are more than 8800 publications in the peer reviewed international literature (PubMed) which describe the resistance of microorganisms against disinfectants and 920 publications on cross resistance with antibiotics [23]. The major drawback however is the sustainability of disinfection of surfaces. In case the surface is decontaminated it can be decontaminated within minutes if the surfaces are touched by a contaminated hand. Traditional cleaning methods are notoriously inefficient for decontamination, and new approaches have been proposed, steam, automated dispersal systems, and antimicrobial surfaces.

There is a law by nature that all substances with antimicrobial activity which require the incorporation of the agent into the metabolism of microorganisms induce resistance [18]. This is well known for antibiotics but also disinfectants. Therefore, it is required that a technology be developed which is not incorporated to the bacterial metabolism but attacks microorganisms from the outside i.e., acid water molecules, free radicals and most important a positive zeta potential i.e., a positive electrostatic charge at the surface which ruptures the phospholipid bilayer of microorganisms upon contact within minutes. Geneva - The tone of the debate over antibiotic resistance is intensifying, with a United Nations Interagency Coordination Group on Antimicrobial Resistance now speaking of a "potentially catastrophic drug resistance crisis" and calling for "immediate, coordinated and ambitious action" upon the release of a new report [8].

Selection of the optimal additive as an in situ generated biocide is of crucial importance. The use of a catalyst is considered a suitable technology as it meets all the basic requirements for the prevention of hospital acquired infections [24].

a. Intensive and broad antimicrobial activity, against Grampositive, Gram-negative microorganisms, irrespective of their 
antibiotic susceptibility, fungi, legionella molds, documented by the RODAC plate method.

b. Many viral pathogens influenza, Epstein Barr virus, herpes, Coronavirus, hepatitis B, C.

c. Fast eradication of microorganisms i.e., minimum $5 \log 10$ reduction within 1 hour.

d. Activity against a high inoculum size of $10^{9} \mathrm{CFU}$ on an area of $3 \mathrm{~cm}^{2}$.

e. No induction of resistance.

f. Nontoxic, skin and soft tissue compatibility, no allergenicity, $\operatorname{sbD}$ (safe by design).

g. Long lasting/permanent antimicrobial activity.

h. Water-, acid-, alkaline-, alcohol, detergent insoluble.

i. UV Light stabile.

j. Cleanable with detergents.

k. Uncomplicated technical processability, heat stabile up to $400^{\circ} \mathrm{C}$, non-corrosive.

l. Physical stability, activity irrespective of sweat, grease, blood, pus.

m. Not flammable, smoke reduction.

n. BP authorisation by the European commission on biocidal products.

o. Favourable cost/benefit analysis.

Catalysts provide antimicrobial activity from ambient water by electron transfer from transition metal oxides embedded in polymers or coatings: [25,26]

a) Formation of $\mathrm{H}_{3} \mathrm{O}^{+}$molecules resulting in an acid $\mathrm{pH}$ of 4.5 like the acid coating of the skin.

b) Formation of free radicals, oxygen radicals as well as hydroxyl radicals.

c) Formation of a positive Zeta potential i.e., a positive electric charge in a $\mu \mathrm{m}$ distance at the surface which attracts electronegative charged microorganisms. Upon contact there is an almost instant disruption of the phospholipid bilayer of the microorganisms and death of the germ. This can be recognised by the staining of the microorganisms with propidium Iodide which stains selectively the DNA of microorganisms red, once it diffuses thought the disrupted phospholipid membrane into the germ. The death of microorganisms has been detected by laser scanning microscopy within 15 minutes on surfaces endowed with in situ generated biocides.

d) Also, paramagnetic ions are formed on a surface with antimicrobial activity.

\section{Preparation of Samples}

Various surfaces have been prepared with different technologies based on in situ generated biocides with various transition metal oxides. Various catalysts e.g., Molybdenum oxide, tungsten blue oxide have been investigated but showed some adverse events not suitable for application in hospital furniture. Zinc Molybdate is an ideal catalyst for in situ generated biocides for several reasons $[30,31]$.

a. Strong and broad antimicrobial activity has been detected if applied in polymers and various coatings.

b. Zinc Molybdate is a white powder which is water, tensed and alcohol insoluble. The color can be adapted to all desirable colors by color pigments. Using submicron particles $(0.25 \mu \mathrm{m}$ particle size = lambda half) Zinc Molybdate is a transparent coating usable for computer screens etc.

c. Zinc Molybdate is insoluble in water, alcohol, detergents and results in a permanent antimicrobial activity documented for more than 10 years. 1000 cleaning cycles with water and a detergent did not impair the antimicrobial activity.

d. Zinc Molybdate is UV light stabile.

e. Zinc molybdate is not toxic. In essence the ingredients are essential trace elements in the body. Investigations disclosed that surfaces endowed with Zinc Molybdate don't elute any ingredient. The allowable UL [upper limit] is $0.01 \mathrm{mg} / \mathrm{kg} \mathrm{Bw} /$ day, equivalent to $0.6 \mathrm{mg} /$ person/day for adults, which also covers pregnant and lactating women" [32].

f. Zinc Molybdate is flame retardant and smoke suppressant.

The antimicrobial activity is based on the size of the surface not on the concentration of the additive in a polymer or a coating. Therefore, submicron particles show a superior antimicrobial activity compared with particle sizes 5 - $8 \mu \mathrm{m}$. Submicron $(0.25 \mu \mathrm{m})$ size particles can be produced by an ultrasound technique [33] (Figure 1). Further research disclosed the possibility to incorporate the moderately water-soluble molybdenum oxide into the water insoluble tungsten crystal lattice. This resulted in the formation of a new compound i.e., Polyoxometalates with additional favourable properties: e.g., a strong Zeta potential with increased antimicrobial activity against bacterial pathogens and fungi. In addition, a strong activity against moulds, many viral pathogens e.g. influenza virus including enveloped virus (COVID 19) hepatitis B, C, algae has been found $[34,35]$. 


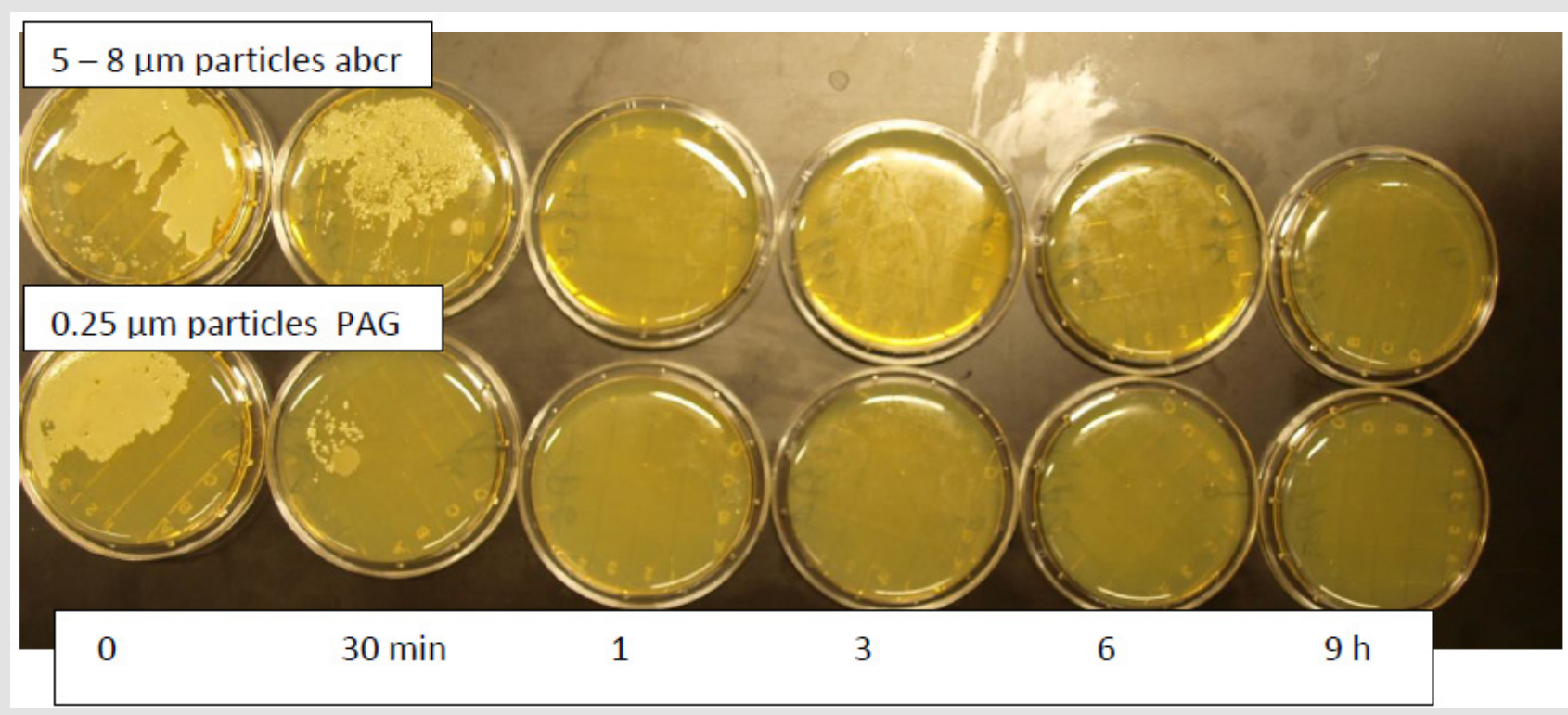

Figure 1.

\section{Samples for Hospital Furniture have Been Produced by Different Techniques}

An absorbent paper has been impregnated with $2 \%$ liquid Zinc Molybdate in melamine resin and applied to particle boards. It has been found that submicron particles ( $0.25 \mu \mathrm{m}$ particle size) added to liquid melamine resin stay in solution for a substantially longer time and does not disintegrate from the surface before the resin is dried. Larger particles ( 5 - $8 \mu \mathrm{m}$ particle size) are separating form the surfaces faster. Therefore, a decreased antimicrobial activity has been detected with particles sizes 5 - $8 \mu \mathrm{m}$ [35].

The endowment of melamine resin coatings of hospital furniture with Zinc Molybdate has been investigated. Surfaces have been endowed with melamine resin containing $3 \%$ of zinc molybdate. A hydrophilic surface is mandatory. In situ generated biocides require a hydrophilic - wettable - surface with a contact angle of a drop of water of less than $30^{\circ}$. The hydrophilicity of the surface is required to reduce the polarity of a waterdrop. By those means the waterdrop becomes wettable something which is constantly achieved by a detergent.

The hydrophilicity of a surface as required can be achieved by a number of hydrophilizing agents e.g. urea, sorbitol ester, glycerine stearate, but also products like Crodamol, Crodaphos, Lubrophos, Fleroxacin which are incorporated into polymers in a concentration of 1 - $2 \%$. Last not least also aerosil could be used as a hydrophilizing agent. AEROSIL ${ }^{\circledR}$ is produced from compounds such as silicon chloride ( $\mathrm{SiCl} 4$ ) by means of flame hydrolysis. The chloride is first vaporized, then mixed with air and hydrogen and forwarded to a combustion chamber. The powdery white silica is created under the flame within a few seconds. The surface exhibits a hydrophilic-wettable surface.
However, the hydrophilicity does not affect the water uptake of a surface! Coating of surface with liquid, transparent, hydrophilic melamine resin coating and additional substrates. Various coatings have been applied as a thin layer on top of a ready to use hospital furniture. This technique can also be used for a retrospective endowment of a melamine resin surfaces already in use. Melamine resin coatings contain $0.2 \%$ of formaldehyde. Formaldehyde is a potent nasal irritant, a cytotoxicant at high doses, and a nasal carcinogen in rats exposed to high airborne concentrations. The normal endogenous concentration of formaldehyde in the blood is approximately $0.1 \mathrm{mM}$ in rats, monkeys, and humans, and it is 2to 4 -fold higher in the liver and nasal mucosa of the rat. Inhaled formaldehyde enters the one-carbon pool, and the carbon atom is rapidly incorporated into macromolecules throughout the body. Oxidation to format catalysed by glutathione-dependent and -independent dehydrogenases in nasal tissues is a major route of detoxication and generally precedes incorporation. The possibility that inhaled formaldehyde might induce various forms of distantsite toxicity has been proposed, but no convincing evidence for such toxicity has been obtained in experimental studies [36,37]. Formaldehyde also evaporates within a matter of 3 weeks.

Soyad adhesive technology is a bio-based, formaldehydefree adhesive system used to produce environmentally friendly hardwood plywood and engineered wood flooring. Soyad adhesives are water-based systems formulated with natural soy flour and a proprietary crosslinking resin. When blended, the resin reacts with the protein in the soy flour to form a durable, water-resistant thermoset adhesive that is comparable in strength and performance to urea-formaldehyde-based adhesives. Soyad adhesives meet all global formaldehyde emission standards. The original adhesive has 
a tan colour. With addition of 3\% Zinc Molybdate applied in a thin coating, a white appearance is obtained. The Soyad adhesive must be cured with a $250^{\circ}$ temperature for approximately 10 minutes. Also, coatings based on silicium dioxide, liquid silicone, liquid polyurethane have been used and result in an optic and haptic attractive surface. Coatings of a surface with a gloss paint where $2 \%$ of Zinc Molybdate is embedded and powder lacquer samples have been prepared.

\section{Investigation of the Antimicrobial Activity}

The endowment of melamine resin with Zinc Molybdate has been investigated. The investigation of the antimicrobial activity of surfaces can be performed by the JIS (Japanese industrial standard) method as recommended by the biocidal product regulation of the European Union and ECHA. The JIS method has been developed for the investigation of the antimicrobial activity of free radicals namely oxygen radicals formed by Titanium oxide. The investigations for antimicrobial activity of melamine resin surfaces endowed with $3 \%$ of Zinc Molybdate have been performed by Hohenstein laboratories (Germany) according to the JIS test: Test report 13.8.3.0075 Hohenstein Laboratories 26. July 26, 2013 showed a strong antimicrobial activity against the test organisms in use i.e., Staphylococcus aureus ATCC 6538, Escherichia coli ATCC 8739 and Pseudomonas aeruginosa ATCC 15776 [38]. Additional tests have been performed using the JIS Test by Ostbayerische Hochschule Weiden. Department medical technology.

Figure 2 shows the investigation of antimicrobial activity of melamine resin surfaces endowed with $2 \%$ of Zinc Molybdate by the JIS method against S. aureus MRSA ATCC 25923. A strong antimicrobial activity (this correlates with a $7 \log 10$ reduction of colony forming units within 1 hours) has been found for $3 \%$ Zinc Molybdate in melamine resin compared with a control without the additive Also with powder lacquers a significant antimicrobial activity has been detected. However, the JIS method is far away from the real-life situation. The oxygen radicals evaporate rapidly from a surface and do not provide a sufficient contact time for the eradication of microorganisms. Therefore, the surface must be covered with a foil. The antimicrobial activity is determined after 24 hours by evaluation of the colony counts on the foil. This method - although approved by an EN norm - is entirely inadequate to draw a conclusion regarding the antimicrobial activity of a surface for prevention of hospital acquired infections.

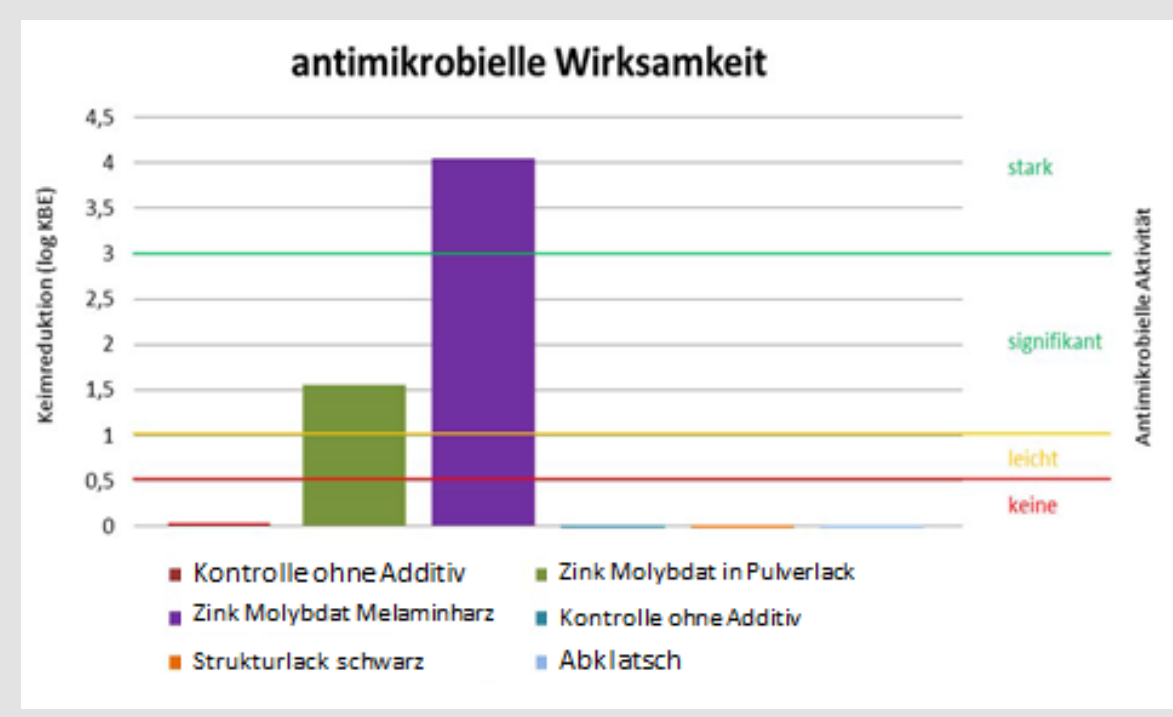

Figure 2.

a) The test determines the antimicrobial activity underneath a foil. Of interest is the antimicrobial activity on the surface.

b) There are non-realistic high concentrations of oxygen radicals in the capillary space between the surface and the foil suggesting a strong antimicrobial activity which is not present under real life conditions.

The relevant method for the determination of self-sanitizing surfaces is therefore the push plate (RODAC replicate organisms' detection and counting) method. The antimicrobial activity of a surfaces which relies exclusively on the formation of free oxygen radicals cannot be determined by the RODAC push plate method i.e., no antimicrobial activity is detected. Additional mechanisms for antimicrobial activity are mandatory.

The push plate method BBL ${ }^{\mathrm{TM}}$ RODAC ${ }^{\mathrm{TM}}$ (Replicate Organism Detection and Counting) is the preferred method for documentation of the number of microorganisms resp. the eradication of microorganisms from a surface [39]. The goal is the fast eradication of microorganisms deposited on surfaces by contamination with hands. This has been investigated initially with the eradication of microorganisms deposited by fingerprints. After contamination of a surface containing $2 \%$ Zinc molybdate in melamine resin in 15 minute intervals the activity has been determined by the push plate (RODAC plate) method (Figure 3). 


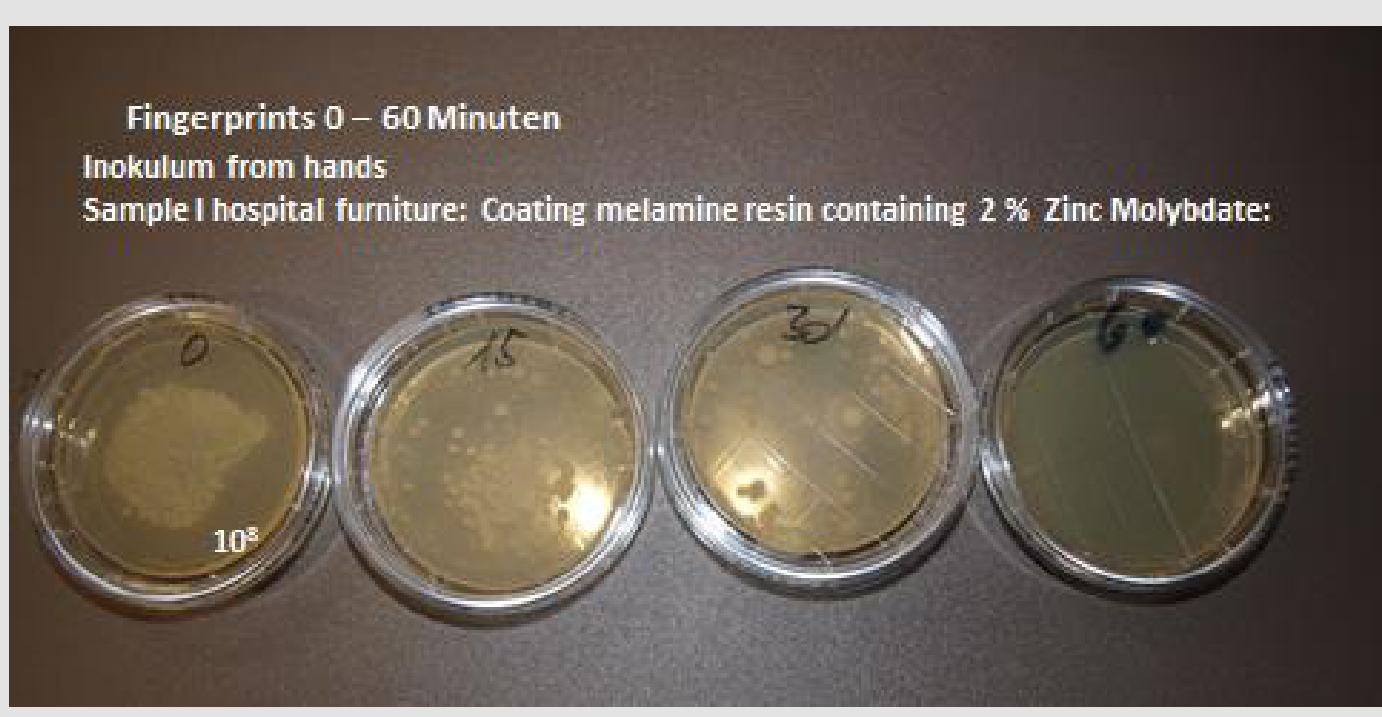

Figure 3.

The original inoculum of $10^{8} \mathrm{CFU}$ (corresponding of bacteria growing as lawn) deposited by a fingerprint has been eradicated completely after 60 minutes. A substantial reduction of the inoculum size is seen already at 15 minutes. After 30 minutes only 25 colonies are observed. This means a reduction of $6 \log 10$ within 30 minutes. It is necessary to copy the real-life situation as close as possible under experimental conditions. It has been found that microorganisms which grow for days on solid medium e.g., on blood agar plates develop a thicker membrane than seen with microorganisms from the skin where microorganisms grow under minimal nutrient conditions. It is remarkable that a lower antimicrobial activity has been observed in microorganisms growing for days on agar plates. Electron microscopic imaging shows a substantially thicker membrane of these microorganisms in contrast to microorganisms from the skin where they grow under minimal nutrient condition.

It is a standard procedure to use new microorganisms for each experiment. Microorganisms are stored on cryopellets at $-35^{\circ} \mathrm{C}$. Two pellets are applied to liquid medium (Isosensitest) at the morning prior to the investigaton; samples are incubated at $37^{\circ} \mathrm{C}$ for 8 hours. In the evening $100 \mu \mathrm{l}$ of the liquid medium is applied to a blood agar plate and incubated at $37^{\circ} \mathrm{C}$. (overnight culture) The next morning microorganisms are harvested in physiologic saline at a concentration of $10^{8} \mathrm{CFU} / \mathrm{ml}$. The concentration has been determined by photometric measurements.

Microorganisms are stored at $-25^{\circ} \mathrm{C} .2$ - 3 cryopellets are transferred in the morning into liquid medium (Isosensitest) and incubated for $6-8$ hours at $37^{\circ} \mathrm{C}$. Reference organisms for investigation including the number of colonies of $10^{8} \mathrm{CFU} / \mathrm{ml}$.

a) Staphylococcus aureus (ATCC 25923) OD of 0.33.

b) Escherichia coli (25922) OD of 0.25 . c) Pseudomonas aeruginosa (DSM 50071). OD of 0.11 .

\section{Procedure}

$10 \mu \mathrm{L}$ of the bacterial suspension is deposited on 6 areas. The suspension is dispersed over the surface. After 10 minutes the samples are dried. Then the investigation starts. At 0 hours, after 1 hour and in 3 hourly intervals until $12-18$ hours the RODAC plates are inoculated at the specified areas of the surface. The RODAC plates are incubated for $18-24$ hours at $37^{\circ} \mathrm{C}$. Determination of the number of colonies forming units on each plate is performed, the results are documented by photography.

\section{Interpretation}

The interpretation of the results is performed by counting the number of colonies on each plate in comparison with a negative control under consideration of an empiric standard deviation. A continuous lawn has been determined as a colony count of $10^{8}$ $\mathrm{CFU} / \mathrm{ml}$. In other instances, the number of colonies were counted and documented. No growth of microorganisms on an agar plate is considered below the level of detection and as less $10 \mathrm{CFU} / \mathrm{ml}$. For each investigation, a positive control (surface with documented activity) and a negative control (surface without antimicrobial activity) is added. A blinded study design is used, one of the samples is a blanc without the additive.

\section{Results of Investigation with the Push Plate Method}

(Figure 4) Three melamine resin coated wood products 214, 215 and 216 have been investigated. 214 contains submicron particles which have been applied with a unique technology not yet disclosed.The antimicrobial activity of samples with a concentration of $2 \%$ applied with different techniques have been investigated at the AmiSTec laboratory and confirmed at the University of Salzburg. Samples 215 and 216 contain the Zinc Molybdate $3 \%$ 
with variations in application. These tests have been performed in a laboratory associated with the Medical Univ. Salzburg, Austria by Prof. Dr. M. Hell. The antimicrobial endowment of particle board sample 214 with a hydrophilic melamine resin coating containing 2\% Zinc Molybdate results in a reduction of microorganisms of 7 $\log 10$ i.e., from $10^{8} \mathrm{CFU} / \mathrm{ml}$ down to less than $>10^{2} \mathrm{CFU} / \mathrm{ml}$ within 1 hour, determined by the RODAC Plate Method. Samples 215 and 216 show eradication of microorganisms after 6 - 9 hours.
Investigations at the Univ. Salzburg. Investigation of above samples by an additional independent investigator. $214 \mathrm{a}=$ old after 1000 cleaning cycles with water and a tensed. $214 \mathrm{n}=$ new production of samples with the same technology. However, the newly produced samples exhibited a lower hydrophilicity, therefore lower activity has been observed. These results demonstrate the importance of a hydrophilic surface with a contact angle of $<30^{\circ}$.
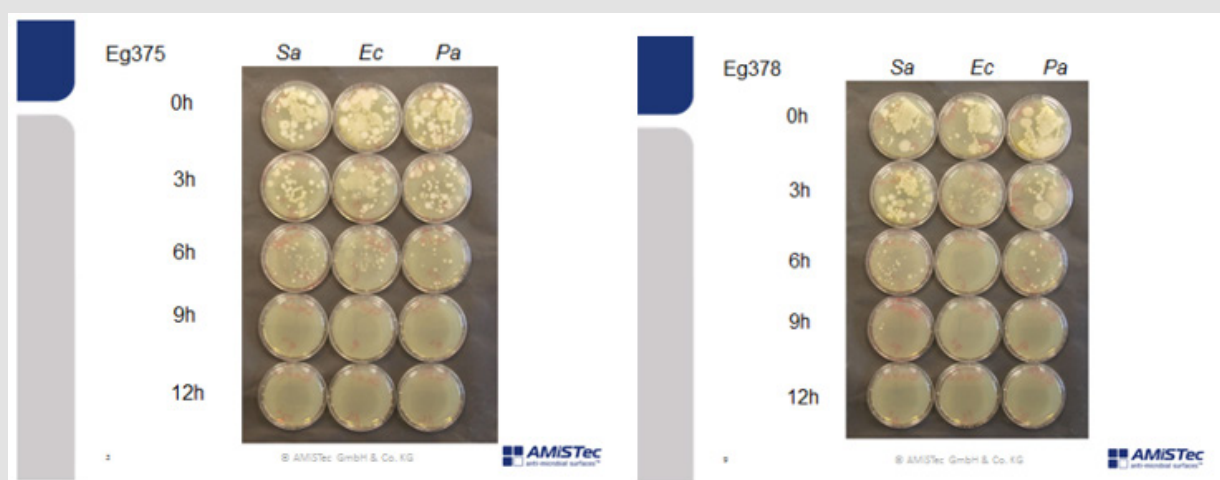

Graphische Darstellung Eg376

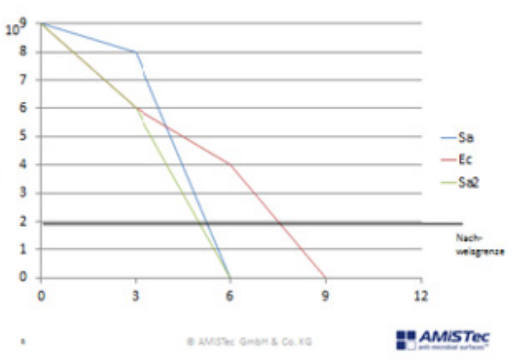

\section{Graphische Darstellung Eg377}

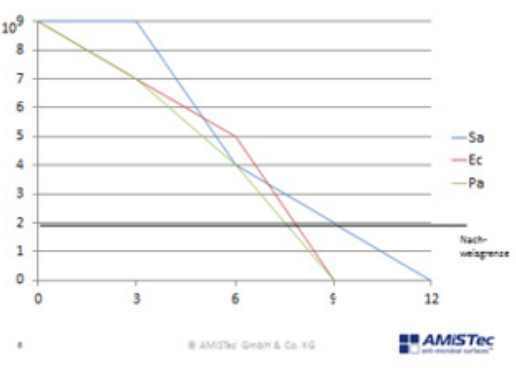

Figure 4 .

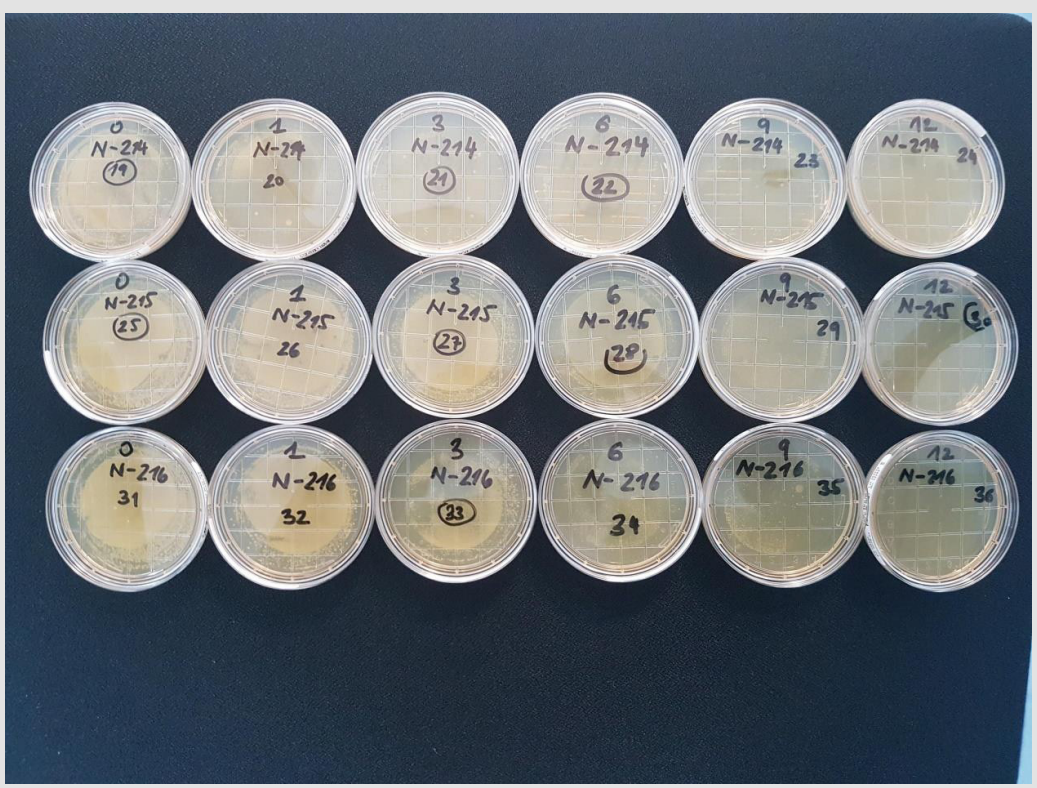

Figure 5. 
Ko is the sample without an additive. 214 a (a stands for 1000 cleaning cycles) and the sample $214 \mathrm{n}$ the have been prepared by the same technology. 214 a: Samples have been cleaned 1000 times with a textile, water and a detergent and show uninhibited excellent antimicrobial activity as the cleaning even exposes additional particles of Zinc Molybdate with antimicrobial activity are to the surface (Figure 5).

It seems that on sample 214 a lower initial bacterial inoculum has been deposited compared to the control without the additive. However, on each site an identical number of microorganisms have been deposited. It is remarkable that at the beginning of the experiment already a substantial reduction of the number of microorganisms has been observed. This observation is explained by the fact that prior to the start of the experiment the bacterial inoculum contained in $100 \mu \mathrm{l}$ of physiologic saline must dry at the surface. During this 15 minute drying period already approximately $35 \%$ of the microorganisms are eradicated. The old samples after 1000 cleaning show even a better antimicrobial activity as with the cleaning additional particles of Zinc Molybdate with antimicrobial activity are exposed to the surface (Figures 6\&7).

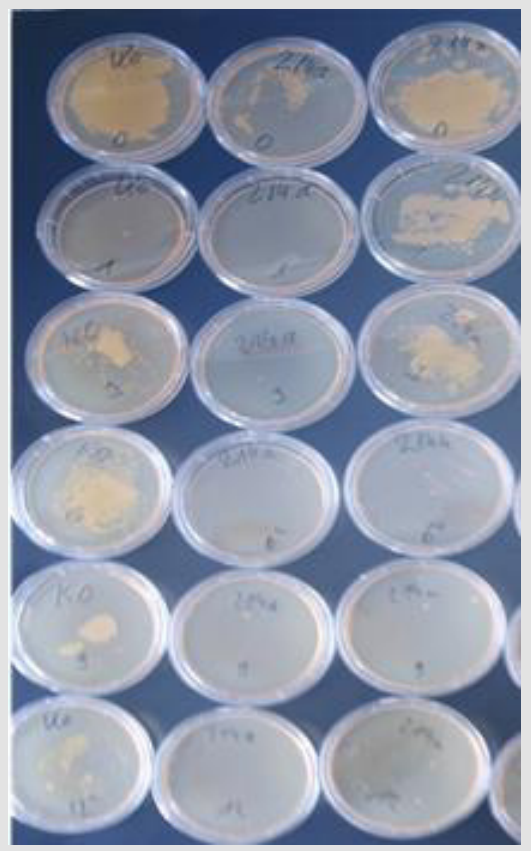

Figure 6.

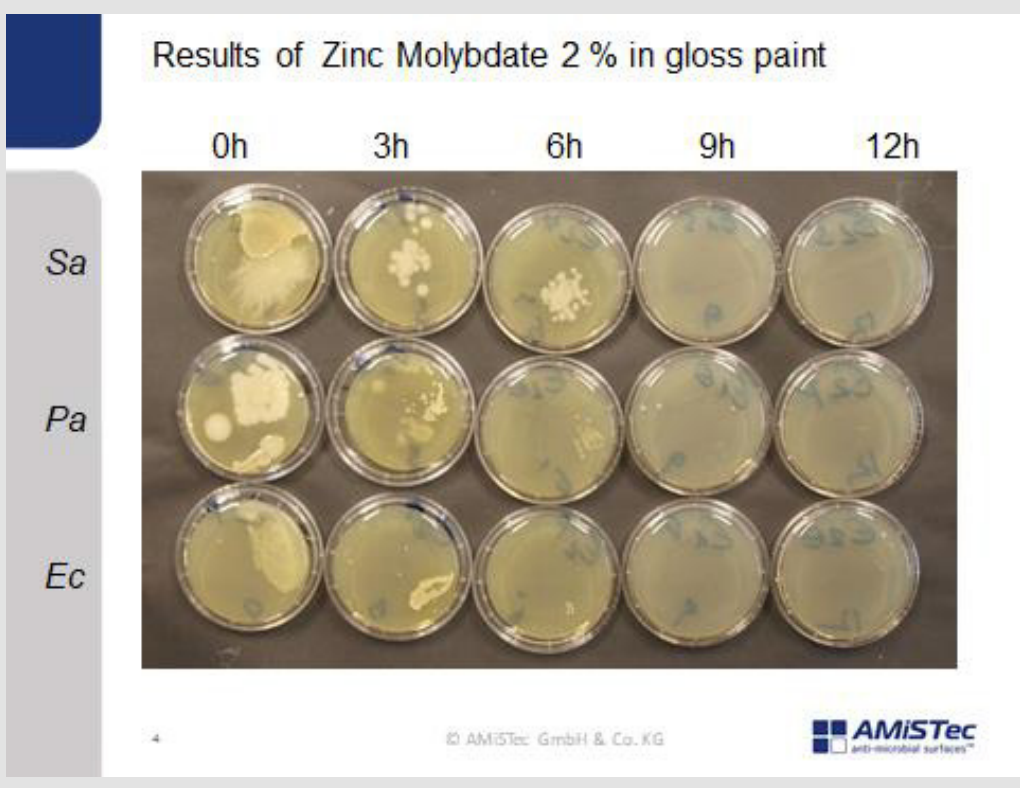

Figure 7. 
Results of $2 \%$ Zinc Molybdate and $2 \%$ Polyoxometalates in a transparent liquid coating: Soyad, a natural, formaldehyde free adhesive (Figure 8). There is a $9 \log 10$ reduction with the polyoxometalate within 30 minutes, after 60 and 90 minutes no microorganisms are observed. Zinc Molybdate shows a substantial decrease of the number of colonies forming units after 30 minutes - the entire inoculum size is eradicated after 60 minutes. Samples have been prepared in 6 weeks so that no formaldehyde is present suggesting an additional antimicrobial efficacy. In addition, no activity has been seen in the control sample without the additives. These results are also confirmed by laser scanning microscopy with a different coating. Zinc Molybdate as well as polyoxometalates (COVID 19 activity $99.22 \%$ reduction within 1 hour) show an excellent antimicrobial activity (Figures 9\&10).

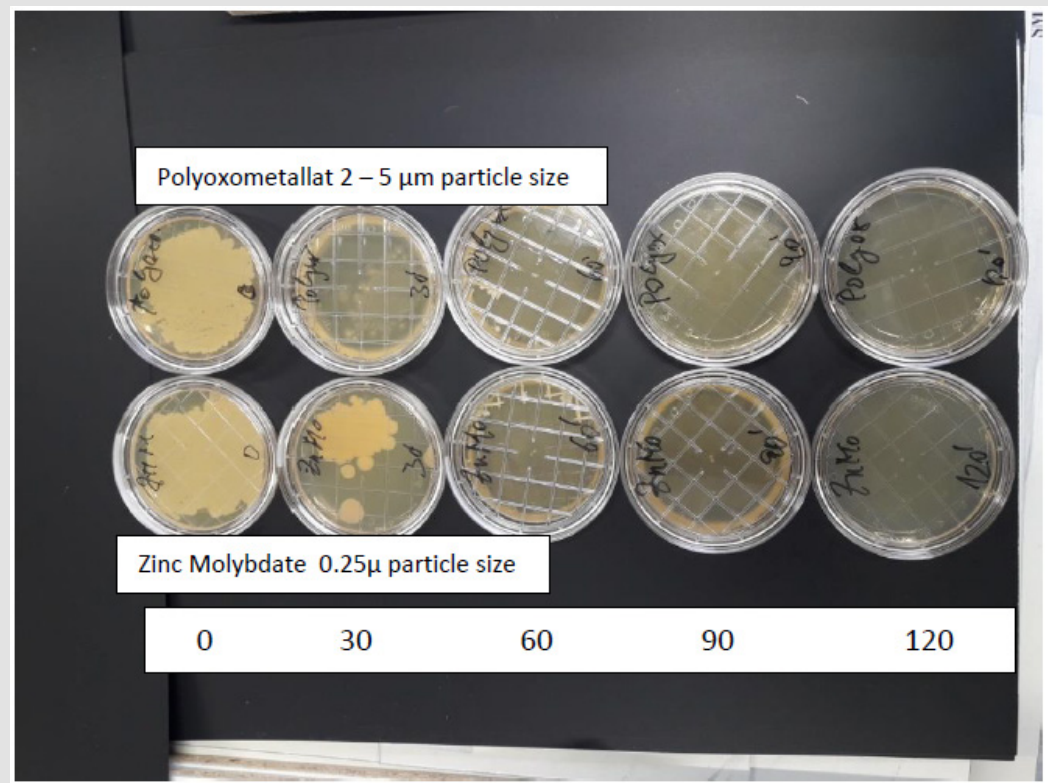

Figure 8.

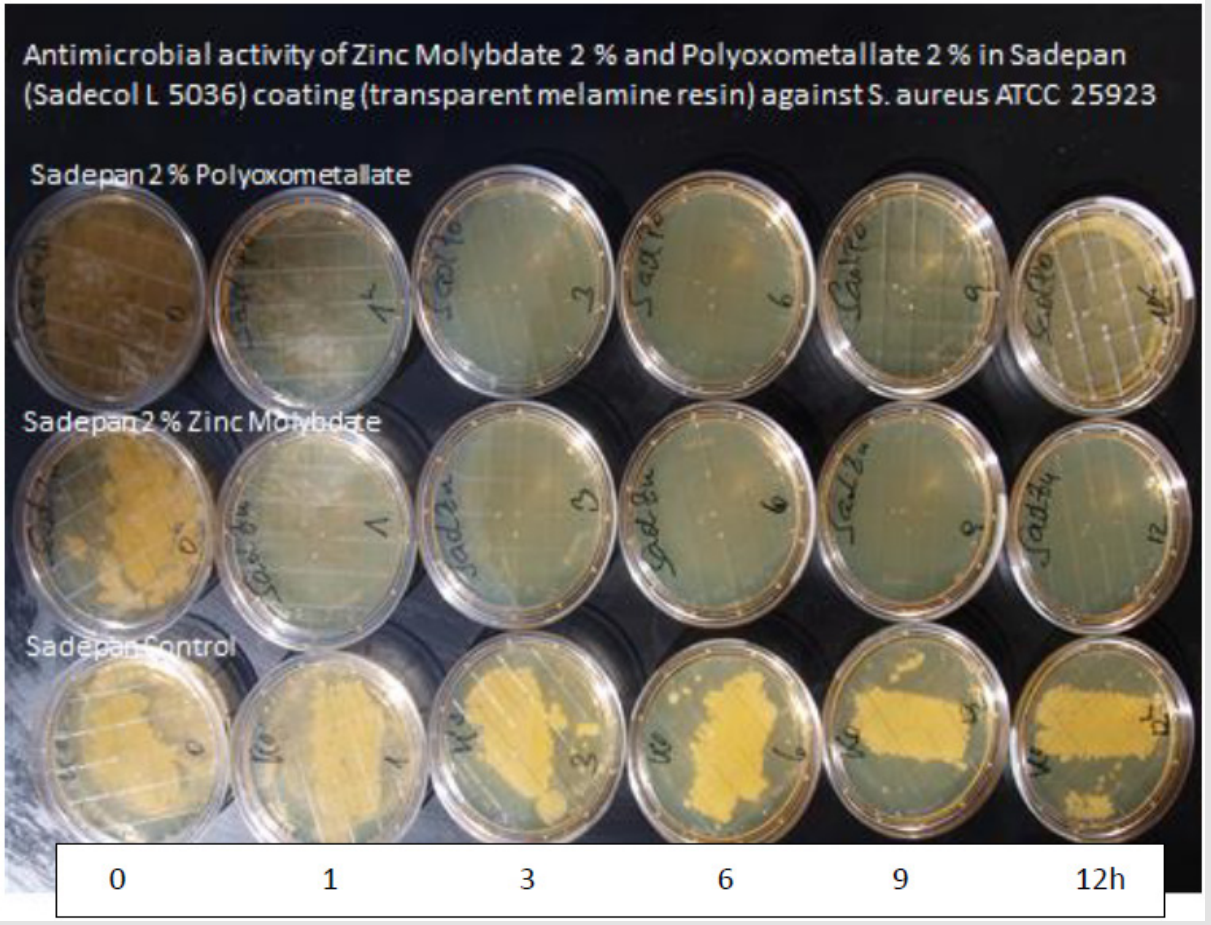

Figure 9. 


\section{Transparente Edelstahlbeschichtug ZnMo $0.25 \%+$ in colloidal Silizium Dioxyd}

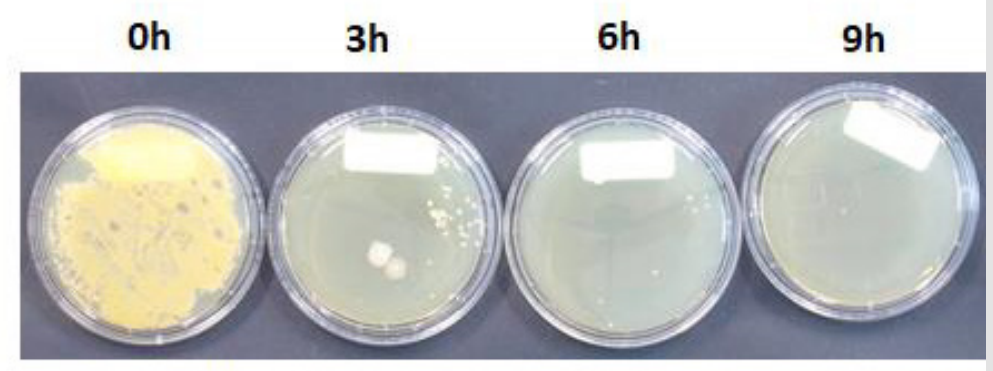

Oberflächen $\mathrm{pH} 3.7$

Figure 10.

It is of great importance to provide self-sanitizing surfaces for the prevention of hospital acquired infections not based on disinfectants. Catalysts provide as in situ generated biocides a fast and reliable permanent antimicrobial activity on surfaces. The surfaces sustain 1000 cleanings, are not toxic in essence the additives are essential trace elements in the body. The technology is effective also against microorganisms in a biofilm as it is not incorporated into the bacterial metabolism. This has a consequence that in situ generated biocides do not induce resistances. These additives can easily apply to virtually every surface [40-44].

\section{References}

1. Vincent JL, Rello J, Marshall J, Silva E, Anzueto A, et al. (2009) International study of the prevalence and outcomes of infection in intensive care units. JAMA 302(21): 2323-2329.

2. Russotto V, Cortegiani A, Graziano G, Saporito L, Raineri SM, et al. (2015) Bloodstream infections in intensive care unit patients: distribution and antibiotic resistance of bacteria. Infect Drug Resist 8: 287-296.

3. Plipat N, Spicknall IH, Koopman JS, Eisenberg JN (2013) The dynamics of methicillin-resistant Staphylococcus aureus exposure in a hospital model and the potential for environmental intervention. BMC Infect Dis 13: 595.

4. Fair R, Tor Y (2014) Antibiotics and Bacterial Resistance in the 21st Century. Perspect Medicine Chem 6(6): 25-64.

5. Tabah A, Koulenti D, Laupland K, Misset B, Valles J, et al. (2012) Characteristics and determinants of outcome of hospital-acquired bloodstream infections in intensive care units: the EUROBACT International Cohort Study. Intensive Care Med 38(12): 1930-1945.

6. Sabino S, Soares S, Ramos FM, Zavascki AP, Rigatto MH (2019) A Cohort Study of the Impact of Carbapenem-Resistant Enterobacteriaceae Infections on Mortality of Patients Presenting with Sepsis. mSphere.

7. Lemmen SW, Häfner H, Zolldann D, Stanzel S, Lütticken (2004) Distribution of multi-resistant Gram-negative versus Gram-positive bacteria in the hospital inanimate environment. R. J Hosp Infect 56(3): 191-197.

8. (2019) Expertengruppe WHO: UN Interagency Coordination Group on Antimicrobial Resistance.

9. Weber DJ, Anderson D, Rutala WA (2013) The role of the surface environment in healthcare-associated infections. Opinion in Infectious Diseases 26(4): 338-344.
10. Kramer A, Schwebke I, Kampf G (2006) How long do nosocomial pathogens persist on inanimate surfaces? A systematic review. BMC Infect Dis 6:130.

11. Han JH, Sullivan N, Leas BF, Pegues DA, Kazmarek JL, et al. (2015) Cleaning Hospital Room Surfaces to Prevent Health Care-Associated Infections: A Technical Brief. Ann Intern Med 163(8): 598-607.

12. Drees M, Snydman DR, Schmid CH, Barefoot L, Hansjosten K, et al. (2008) Prior environmental contamination increases the risk of acquisition of vancomycin-resistant enterococci. Clin Infect Dis 46(5): 678-685.

13. Weber DJ, Anderson D, Rutala WA (2013) The role of the surface environment in healthcare-associated infections. Curr Opin Infect Dis 26(4): 338-344.

14. Russotto V, Cortegiani A, Raineri SM, Giarratano A (2015) Bacterial contamination of inanimate surfaces and equipment in the intensive care unit. J Intensive Care 3(54).

15. Huang SS, Datta R, Platt R (2006) Risk of acquiring antibiotic-resistant bacteria from prior room occupants. Arch Intern Med 166(18): 19451951.

16. Hayden MK, Blom DW, Lyle EA, Moore CG, Weinstein RA (2008) Risk of hand or glove contamination after contact with patients colonized with vancomycin-resistant enterococcus or the colonized patients' environment. Infect Control 29(02): 149-154.

17. Nseir S, Blazejewski C, Lubret R, Wallet F, Courcol R, et al. (2011) Risk of acquiring multidrug-resistant Gram-negative bacilli from prior room occupants in the intensive care unit. Clin Microbiol Infect 17(8): 12011208.

18. Mc Carlie S, Boucher CE, Bragg RR (2020) Molecular basis of bacterial disinfectant resistance. Drug Resist Updat 48.

19. Seki M, Machida N, Yamagishi Y, Yoshida H, Tomono K (2013) Nosocomial outbreak of multidrug-resistant Pseudomonas aeruginosa caused by damaged transesophageal echocardiogram probe used in cardiovascular surgical operations. J Infect Chemother 19(4): 677-681.

20. (2018) Report: Prof. Dr. John Walker at the yearly nobel laureate meeting Lindau Germany. Spiegel online.

21. Møretrø T, Schirmer BCT, Heir E, Fagerlund A, Hjemli P, et al. (2017) Tolerance to quaternary ammonium compound disinfectants may enhance growth of Listeria monocytogenes in the food industry. Int J Food Microbiol 241: 215-224.

22. Falk PS, Winnike J, Woodmansee C, Desai M, Mayhall CG (2000) Outbreak of vancomycin-resistant enterococci in a burn unit. Infect Control 21(09): 575-582.

23. Gaillot O, Maruéjouls C, Abachin É, Lecuru F, Arlet G, et al. (1998) Nosocomial outbreak of Klebsiella pneumoniae producing SHV-5 
extended-spectrum $\beta$-lactamase, originating from a contaminated ultrasonography coupling gel. J Clin Microbiol 36(5): 1357-1360.

24. Zollfrank C, Gutbrod K, Wechsler P, GuggenbichlerJP (2012) Antimicrobial activity of transition metal acid $\mathrm{MoO}(3)$ prevents microbial growth on material surfaces. Mater Sci Eng C Mater Biol Appl 32(1): 47-54.

25. Lackner M, Maninger S, Guggenbichler JP (2013) Saure Oberflächen als neuartige Kontaktbiozide. Nachr Chem 61(2):112-115.

26. Tabah A, Koulenti D, Laupland K, Misset B, Valles J, et al. (2012) Characteristics and determinants of outcome of hospital-acquired bloodstream infections in intensive care units: the EUROBACT International Cohort Study. Intensive Care Med 38(12): 1930-1945.

27. Albarqouni L, Byambasuren O, Clark J, Scott AM, Looke D, et al. (2020) Does copper treatment of commonly touched surfaces reduce healthcare-acquired infections? A systematic review and meta-analysis. J Hosp Infect 106(4): 765-773.

28. Christoff AP, Sereia AFR, Cruz GNF, Bastiani DC, Silva VL, et al. (2020) One year cross-sectional study in adult and neonatal intensive care units reveals the bacterial and antimicrobial resistance genes profiles in patients and hospital surfaces. PLoS One eCollection 15(6).

29. Dancer SJ (2014) Controlling hospital-acquired infection: focus on the role of the environment and new technologies for decontamination. Clin Microbiol Rev 27(4): 665-690.

30. Fernando SA, Gray TJ, Gottlieb T (2017) Healthcare-acquired infections: prevention strategies. Intern Med J 47(12): 1341-1351.

31. (2000) Toxicological Risks of Selected Flame-Retardant Chemicals National Research Council (US) Subcommittee on Flame-Retardant Chemicals. Washington (DC): National Academies Press (US).

32. www.efsa.europa.eu/de/ndatopics/docs/ndatolerableuil.pdf

33. Patel MA, Bhanvase BA, Sonawane SH. Ultrason (2013) Production of cerium zinc molybdate nano pigment by innovative ultrasound assisted approach. Sonochem 20(3): 906-913.

34. Čolović MB, Lacković M, Lalatović J, Mougharbel AS, Kortz U, et al. (2020) Polyoxometalates in Biomedicine: Update and Overview. Curr Med Chem 27(3): 362-379.

ISSN: 2574-1241

DOI: 10.26717/BJSTR.2021.35.005737

Guggenbichler JP. Biomed J Sci \& Tech Res

(C) This work is licensed under Creative Commons Attribution 4.0 License

Submission Link: https://biomedres.us/submit-manuscript.php
35. Hu D, Shao C, Guan W, Su Z, Sun J, et al. (2007) Studies on the interactions of Ti-containing polyoxometalates (POMs) with SARS-CoV 3CLpro by molecular modeling. J Inorg Biochem 101(1): 89-94.

36. D'A Heck H, Casanova M (2004) The implausibility of leukemia induction by formaldehyde: a critical review of the biological evidence on distantsite toxicity. Regul Toxicol Pharmacol 40(2): 92-106.

37. Allegra A, Spatari G, Mattioli S, Curti S, Innao V, et al. (2019) Formaldehyde Exposure and Acute Myeloid Leukemia: A Review of the Literature. Medicina (Kaunas) 55(10): 638.

38. (2013) Test report 13.8.3.0075 Hohenstein Laboratories.

39. Edmiston CE Jr, Spencer M, Lewis BD, Rossi PJ, Brown KR, et al. (2020) Assessment of a novel antimicrobial surface disinfectant on inert surfaces in the intensive care unit environment using ATP-bioluminesence assay. D. Am J Infect Control 48(2): 143-146.

40. Migliara G, Di Paolo C, Barbato D, Baccolini V, Salerno C, et al. (2019) Multimodal surveillance of healthcare associated infections in an intensive care unit of a large teaching hospital. Ann Ig 31(5): 399-413.

41. Galvin S, Dolan A, Cahill O, Daniels S, Humphreys H (2012) Microbial monitoring of the hospital environment: why and how? J Hosp Infect 82(3): 143 .

42. Weber DJ, Rutala WA, Miller MB, Huslage K, Sickbert-Bennett E (2010) Role of hospital surfaces in the transmission of emerging health careassociated pathogens: norovirus, Clostridium difficile, and Acinetobacter species. Am J Infect Control 38(5): S25-S33.

43. Huang SS, Datta R, Platt R (2006) Risk of acquiring antibiotic-resistant bacteria from prior room occupants. Arch Intern Med 166(18): 19451951.

44. Bassetti M, Giacobbe DR, Giamarellou H, Viscoli C, Daikos GL, et al. (2018) Management of KPC-producing Klebsiella pneumoniae infections. Critically Ill Patients Study Group of the European Society of Clinical Microbiology and Infectious Disease (ESCMID); Hellenic Society of Chemotherapy (HSC) and Società Italiana di Terapia Antinfettiva (SITA). Clin Microbiol Infect 24(2): 133-144.

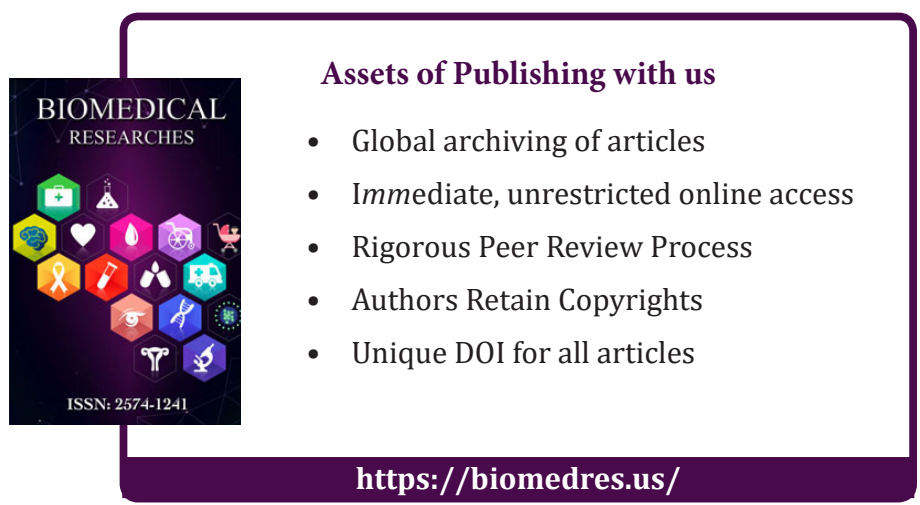

